\title{
Forkhead box 01 promotes INS-1 cell apoptosis by reducing the expression of $\mathrm{CD} 24$
}

\author{
YUHANG MA* , XUEJIAO WANG* ${ }^{*}$ YONGDE PENG and XIAOYING DING \\ Department of Endocrinology and Metabolism, Shanghai First People's Hospital, \\ Shanghai Jiao Tong University, Shanghai 200080, P.R. China
}

Received March 10, 2015; Accepted January 20, 2016

DOI: $10.3892 / \mathrm{mmr} .2016 .4896$

\begin{abstract}
Type 2 diabetes seriously affects human health and burdens public health systems. Pancreatic $\beta$-cell apoptosis contributes to a reduction in $\beta$-cell mass, which is responsible for the occurrence of type 2 diabetes. However, the mechanism that underlies this effect remains unclear. In the present study, the role of forkhead box O1 (Foxol) was investigated (which is a key regulatory factor in $\beta$-cell function) in the apoptotic behavior of $\beta$-cells and a potential underlying mechanism was determined. It was demonstrated that Foxol overexpression significantly reduced the proliferation of INS-1 cells and increased the apoptosis of INS-1 cells, in contrast to foxm1, foxp, foxa1, foxc and foxb1 overexpression. The present study aimed to investigate potential underlying mechanisms using bioinformatics, including Gene Set Enrichment Analysis, and biological experiments, including flow cytometry, cell counting kit-8, immunofluorescence, western blotting, reverse transcription-quantitative polymerase chain reaction analysis and lentiviral transfection. Further experiments conclusively showed that cluster of differentiation (CD)24 expression was significantly decreased when INS-1 cells were treated with Foxo1. Animal experiments showed high CD24 expression in the pancreatic islets of diabetic Goto-Kakizaki rats. Moreover, Gene Set Enrichment Analysis showed that CD24 expression was associated with the adaptive immune response
\end{abstract}

Correspondence to: Dr Yongde Peng or Dr Xiaoying Ding, Department of Endocrinology and Metabolism, Shanghai First People's Hospital, Shanghai Jiao Tong University, 100 Haining Road, Shanghai 200080, P.R. China

E-mail: pengyongde0908@126.com

E-mail: xiaoyingding@126.com

${ }^{*}$ Contributed equally

Abbreviations: Foxo1, forkhead box O1; Foxm1, forkhead box M1; Foxp, forkhead box p2; Foxa1, forkhead box A1; Foxc, forkhead box C; Foxb1, forkhead box b1; CD24, cluster of differentiation 24; ZAP70, $\zeta$-chain-associated protein kinase 70 ; PTAFR, platelet-activating factor receptor; TMEM14, transmembrane protein 14

Key words: diabetes, Foxo1, CD24, INS-1, apoptosis of $\beta$-cells. Finally, no significant differences in the proliferation and apoptosis of CD24 overexpressing INS-1 cells were observed after Foxol treatment. These results suggested that Foxol overexpression in $\beta$-cells was able to increase apoptosis by inhibiting CD24 expression. This study may provide an approach for the treatment and prevention of type 2 diabetes.

\section{Introduction}

Over the past three decades, the number of patients with diabetes mellitus has increased rapidly; $90 \%$ of these patients suffer from type 2 diabetes mellitus, rendering type 2 diabetes one of the most serious public health challenges worldwide (1). Type 2 diabetes mellitus is an endocrine system disease that results from $\beta$-cell dysfunction. $\beta$-cell dysfunction is characterized by the specific absence of the first phase of glucose-induced insulin secretion (2). Pancreatic $\beta$-cells are responsible for abnormal glucose metabolism due to defects in insulin secretion or due to a loss of $\beta$-cell mass resulting from cell death $(3,4)$. Apoptosis constitutes the primary form of $\beta$-cell death (5-7); however, the underlying mechanisms remain unclear.

The transcription factor, forkhead box O1 (Foxo1), is a key regulator of pancreatic $\beta$-cell mass; however, the role of Foxo1 in the maintenance of $\beta$-cell function remains controversial (8). A previous study provided a mechanism linking glucose- and growth factor receptor-activated pathways to protect $\beta$-cells against oxidative damage via Foxo1 (9). Kitamura et al (10) reported that Foxo1 could inhibit the expression of the $\beta$-cell-specific transcription factor $\mathrm{Pdx} 1$ and that this led to the impairment of $\beta$-cell neogenesis, which should be responsible for a reduction in $\beta$-cell mass. Other studies have also reported that the suppression of Foxol expression reduces the expression of apoptotic markers and promotes $\beta$-cell survival in type 2 diabetes (9-12). However, further studies are required to determine the role of Foxo1 in $\beta$-cells.

Cluster of differentiation (CD)24 is a glycoprotein expressed in a wide variety of human malignancies, such as renal cell carcinoma, $\beta$-cell lymphoma, small cell and non-small cell lung carcinoma, epithelial ovarian cancer, and breast cancer (13-16). However, little is known regarding the correlation between CD24 expression and $\beta$-cell function.

The aim of the present study was two-fold, to determine whether Foxol could promote $\beta$-cell apoptosis and to examine 
the association between Foxo1 and CD24, and the effect of CD24 expression on $\beta$-cell function. The results of this study may provide a novel approach for the treatment and prevention of type 2 diabetes.

\section{Materials and methods}

Materials. RPMI-1640, HEPES, fetal bovine serum (FBS), L-glutamine, Lipofectamine 2000 transfection reagent, TRIzol reagent, a PureLink RNA Mini kit, and a High Capacity cDNA Reverse Transcription kit were obtained from Invitrogen, Thermo Fisher Scientific, Inc. (Waltham, MA, USA). Sodium pyruvate, $\beta$-mercaptoethanol and Cell counting kit-8 were purchased from Sigma-Aldrich (St. Louis, MO, USA). pcDNA3-Foxo1, pcDNA3-Foxm1, pcDNA3-Foxp, pcDNA3-Foxa1, pcDNA3-Foxc and pcDNA3-Foxb1 were purchased from Fujian Funeng Co., Ltd. (Shanghai, China). Rat INS-1 pancreatic $\beta$-cells were obtained from the China Center for Type Culture Collection (Shanghai, China). An Apoptosis Detection kit was purchased from KeyGEN Biotech (Shanghai, China). Real-time PCR primers, which included primers against CD24, ZAP70, PTAFR, TMEM14 and SPOCK2, were custom-synthesized by Invitrogen, Thermo Fisher Scientific, Inc. Rabbit polyclonal anti-rat CD24 antibodies were purchased from Santa Cruz Biotechnology, Inc., Dallas, TX, USA (cat. no. sc-11406; dilution, 1:200) and mouse monoclonal anti-rat $\beta$-actin primary antibodies were purchased from Abcam, Cambridge, UK (cat. no. ab6276; dilution, 1:10,000). The secondary antibodies were mouse anti-rabbit IgG (dilution, 1:100; cat. no. 211-005-109) and rabbit anti-mouse IgG (dilution, 1:200; cat. no. 315-0005-003) horseradish peroxidase (HRP)-conjugated antibodies, which were purchased from Jackson ImmunoResearch Laboratories, Inc. (West Grove, PA, USA). The present study was performed according to the National Institutes of Health Guide for the Care and Use of Laboratory Animals (17) and the guidelines for animal experiments and associated activities by the ethics committee of Shanghai First Central Hospital, and was approved by the ethics committee of Shanghai First People's Hospital, Shanghai Jiao Tong University School of Medicine (Shanghai, China).

INS-1 cell culture. Rat INS-1 pancreatic $\beta$-cells were cultured in RPMI-1640 medium containing $11 \mathrm{mM}$ glucose, $1 \mathrm{mM}$ sodium pyruvate, $10 \mathrm{mM}$ HEPES, $10 \% \mathrm{FBS}, 2 \mathrm{mM}$ glutamine, and $50 \mu \mathrm{M} \beta$-mercaptoethanol at $37^{\circ} \mathrm{C}$ in a $5 \% \mathrm{CO}_{2}$ incubator. The medium was refreshed every 2 days.

INS-1 cell transfections. Prior to transfection, INS-1 cells were seeded in 6-well plates at a density of $2 \times 10^{6}$ cells/well until the cells grew to $>80 \%$ confluence. Then, the cells were transfected with $2 \mu \mathrm{g}$ pcDNA3-Foxo1, pcDNA3-Foxm1, pcDNA3-Foxp, pcDNA3-Foxa1, pcDNA3-Foxc or pcDNA3-Foxb1 using Lipofectamine 2000 transfection reagent according to the manufacturer's instructions. Opti-MEM I (50 $\mu \mathrm{l}$; Invitrogen; Thermo Fisher Scientific, Inc.) containing $2 \mu \mathrm{g}$ plasmid was mixed with Opti-MEM I containing $2 \mu 1$ Lipofectamine 2000 and incubated for $20 \mathrm{~min}$ at room temperature. The medium was placed in a 6-well plate $(100 \mu 1 /$ well $)$ and cultured at $37^{\circ} \mathrm{C}$ in a $5 \% \mathrm{CO}_{2}$ inhibitor for $72 \mathrm{~h}$. pcDNA3 was used as a control. The transfection medium was replaced with regular growth medium (RPMI-1640 medium with $11 \mathrm{mmol} / 1 \mathrm{D}$-glucose supplemented with $10 \%$ FBS, $100 \mathrm{U} / \mathrm{ml}$ penicillin, $10 \mu \mathrm{g} / \mathrm{ml}$ streptomycin, $10 \mathrm{mmol} / 1 \mathrm{HEPES}, 2 \mathrm{mmol} / \mathrm{l} \mathrm{L}$-glutamine, $1 \mathrm{mmol} / 1$ sodium pyruvate and $50 \mu \mathrm{mol} / 1 \beta$-mercaptoethanol) after $5 \mathrm{~h}$, and the cells were observed at each indicated time point using an inverted fluorescence microscope (DMI 6000B; Leica Microsystems GmbH, Wetzlar, Germany).

Cell counting kit (CCK)-8 tests. INS-1 cells transfected with Foxo1 were seeded in 96-well plates at a density of $1 \times 10^{5}$ cells per well for $24 \mathrm{~h}$. Then, 10, 20 or $40 \mathrm{mM}$ Foxol was added, and the cells were continuously cultured for 24 or $72 \mathrm{~h}$. Untreated cells were used as a negative control, and dimethyl sulfoxide-treated cells were used as a positive control. At the indicated times, $10 \mu \mathrm{l}$ CCK-8 (Sigma-Aldrich) was added, and the plates were incubated for $3 \mathrm{~h}$. After this period, the absorbance was measured at $450 \mathrm{~nm}$ using a microplate reader (Multiskan ${ }^{\circledR}$ Spectrum; Thermo Fisher Scientific, Inc.).

Apoptosis assays. Apoptosis was analyzed using an Annexin V-FITC Apoptosis Detection kit (KeyGEN Biotech) according to the manufacturer's instructions. Foxo1-transfected INS-1 cells were cultured in 6-well plates at a density of $1 \times 10^{5}$ cells per well for 2 days. Adherent INS-1 cells at $80 \%$ confluence were passaged with $0.125 \%$ trypsin- $0.02 \%$ EDTA (Invitrogen; Thermo Fisher Scientific, Inc.) and inoculated at a density of $2 \times 10^{4}$ in 24-well culture dishes in growth medium as described above. At the indicated times, the cells were digested with $0.25 \%$ trypsin and washed with pre-cooled phosphate-buffered saline (PBS; Gibco; Thermo Fisher Scientific, Inc.). Binding buffer $(300 \mu \mathrm{l})$ containing $5 \mu \mathrm{l}$ Annexin V-fluorescein isothiocyanate (FITC) was added and incubated at room temperature in the dark for $15 \mathrm{~min}$. Subsequently, $5 \mu \mathrm{l}$ propidium iodide (PI) solution was added and incubated at room temperature in the dark for $15 \mathrm{~min}$. The stained cells were measured and analyzed in a BD FACSCalibur ${ }^{\mathrm{TM}}$ (BD Biosciences, Franklin Lakes, NJ, USA by CellQuest software (version 1.1; BD Biosciences).

Reverse transcription-quantitative polymerase chain reaction $(R T-q P C R)$. Rat pancreases were obtained from male Goto-Kakizaki (GK) rats $(\mathrm{n}=8$; age, 7 weeks; weight, 260-300 g) and Sprague Dawley rats $(\mathrm{n}=8$; age, 7 weeks; weight, 260-300 g) serving as a control, which were obtained from Shanghai SLAC Laboratory Animal Co., Ltd. (Shanghai, China). These animals were maintained in a standard animal laboratory with free activity and free access to water and food. They were maintained in a temperature-controlled environment at $22-24^{\circ} \mathrm{C}$, relative humidity of $40-60 \%$, with a $12-\mathrm{h}$ light/dark cycle. The rats were fasted for $8 \mathrm{~h}$ prior to surgery and were sacrificed by exsanguination under anesthesia with $40 \mathrm{mg} / \mathrm{kg}$ sodium pentobarbital (Sigma-Aldrich), and maximal efforts were made to minimize suffering. Rat islet cells were digested using collagenase P (Roche Diagnostics, Basel, Switzerland) and purified by Ficoll density separation with Eurocollins (Mediatech, Inc., Herndon, VA, USA) using a previously described method (18). The cells released were then resuspended in growth medium as described above. The pancreatic islet cells obtained from GK rats (age, 7 weeks) 


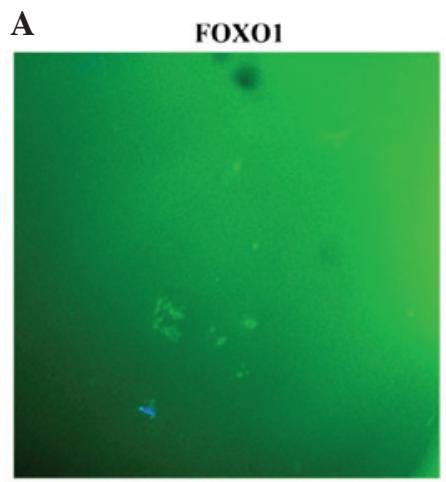

$\mathbf{B}$

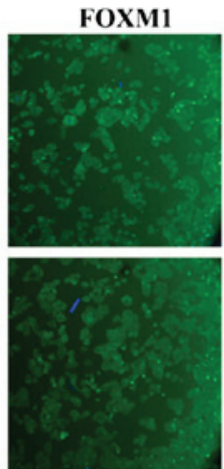

FOXC

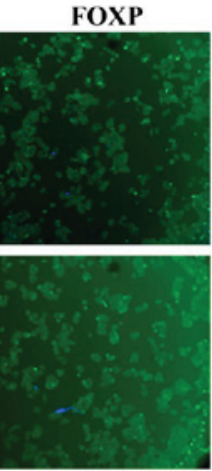

FOXB1

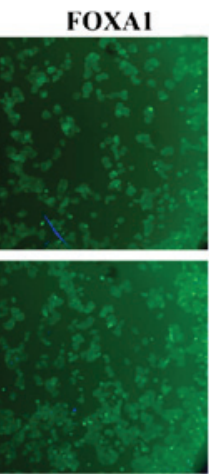

pCDNA3

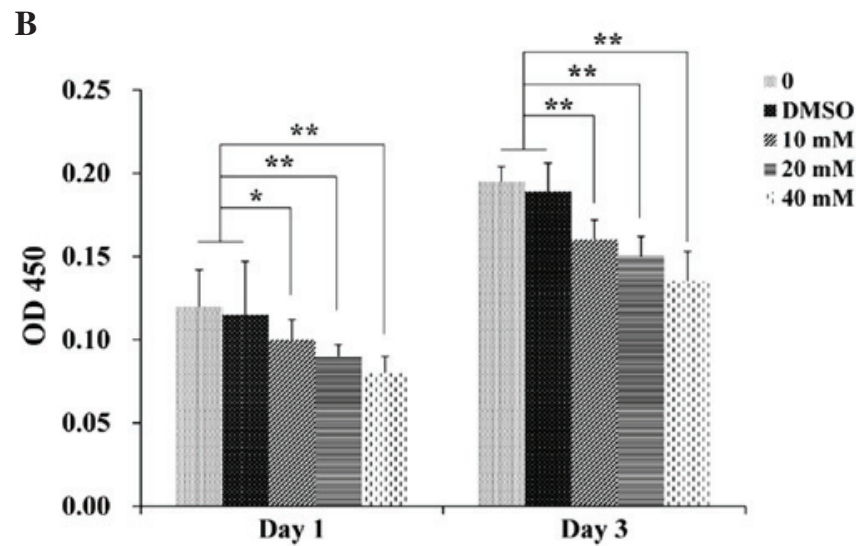

Figure 1. Foxo1 inhibits INS-1 cell proliferation. (A) INS-1 cell proliferation 3 days after treatment with Foxo1, foxm1, foxp, foxa1, foxc, or foxb1 using immunofluorescent assay. Magnification, x100. (B) Proliferation tests of INS-1 cells treated with 10,20 or $40 \mathrm{mM}$ Foxol on days 1 and 3. "P<0.05, " $\mathrm{P}<0.01$. DMSO, dimethyl sulfoxide; OD, optical density; fox, forkhead box.

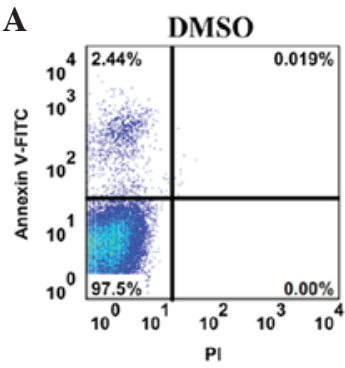

$20 \mathrm{mM}$

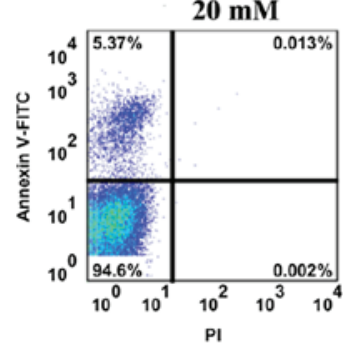

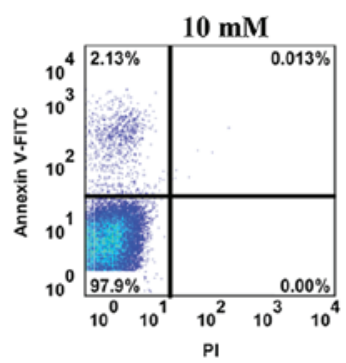

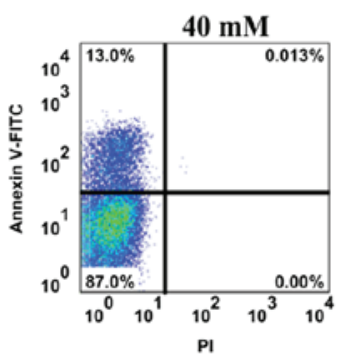

B

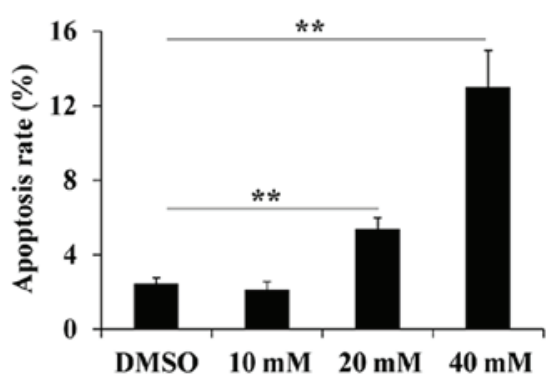

Figure 2. Foxol promotes INS-1 cell apoptosis by flow cytometry. (A) The apoptosis rate of INS-1 cells treated with 10,20 or 40 mM Foxo1; the control group was treated with DMSO. (B) Statistical analysis of INS-1 cell apoptosis after treatment with different concentrations of Foxo1. Fox, forkhead box; DMSO, dimethyl sulfoxide; FITC, fluorescein isothocyanate; PI, propidium iodide.

were ground to a powder with liquid nitrogen. Then, the powders of INS-1 cells that received different treatments were lysed using TRIzol reagent, and total RNA was purified using a PureLink RNA Mini kit. The purified RNA $(0.5 \mu \mathrm{g})$ was reverse-transcribed into cDNA using a High Capacity cDNA
Reverse Transcription kit at $42^{\circ} \mathrm{C}$ for $1 \mathrm{~h}$, followed by $85^{\circ} \mathrm{C}$ for $5 \mathrm{sec}$. The cDNA produced was diluted 5 -fold and used as the PCR template. PCR was performed with SYBR ${ }^{\circledR}$ Premix Ex Taq kit (containing No AmpErase UNG, $0.4 \mu 1$ primer mixture (each $10 \mu \mathrm{M}$ ) and $7.6 \mu \mathrm{l}$ double distilled water) to detect CD24, 

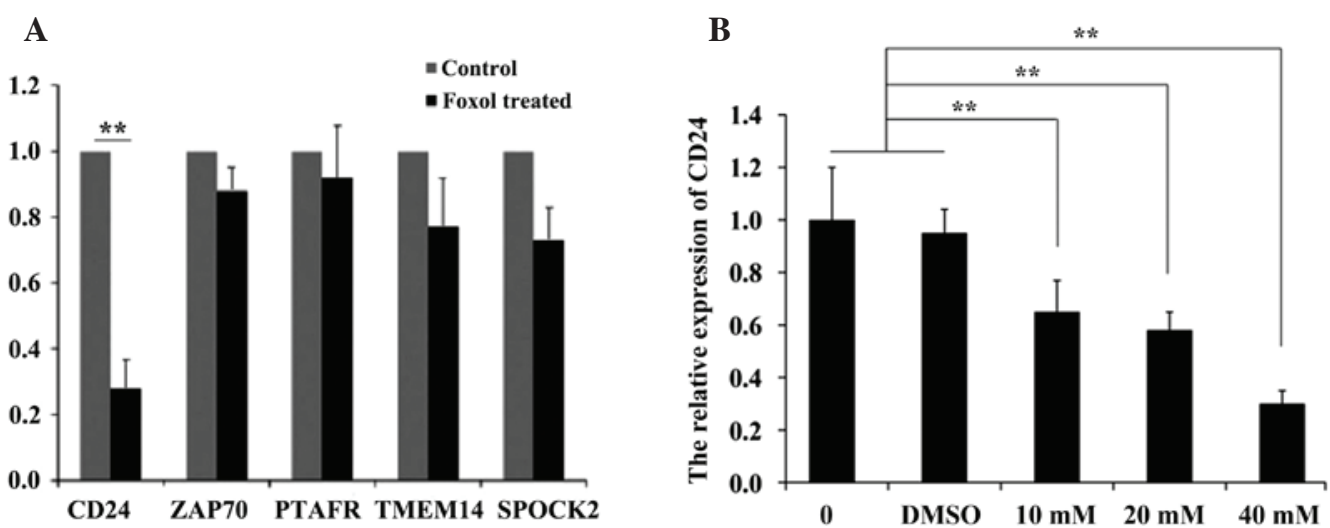

Figure 3. Foxo1 suppresses CD24 expression in INS-1 cells. (A) The expression analysis of five genes in INS-1 cells overexpressing Foxo1 as analyzed by reverse transcription-quantitative polymerase chain reaction. (B) CD24 expression in INS-1 cells following treatment with 10,20 or $40 \mathrm{mM}$ Foxo1. ** P<0.01. FOX, forkhead box; CD, cluster of differentiation; ZAP70, $\zeta$-chain-associated protein kinase 70; PTAFR, platelet-activating factor receptor; TMEM14, transmembrane protein 14; DMSO, dimethyl sulfoxide.

A

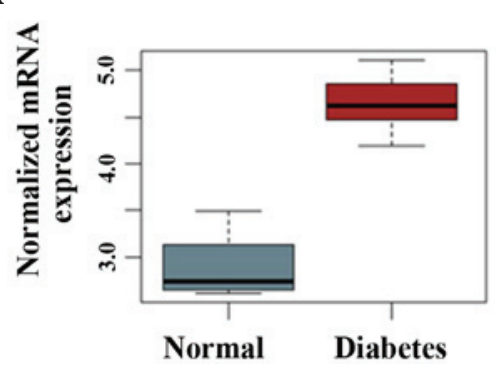

B

CD24

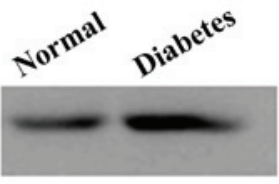

Actin

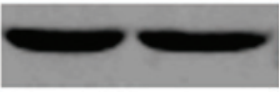

Figure 4. CD24 is highly expressed in the pancreatic islets of diabetic Goto-Kakizaki rats as analyzed by reverse transcription-quantitative polymerase chain reaction and western blotting. CD24 (A) mRNA and (B) protein expression in normal animals and in a diabetes model. CD, cluster of differentiation.

A

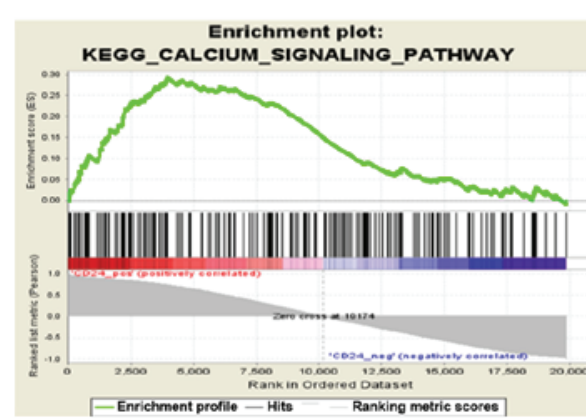

B

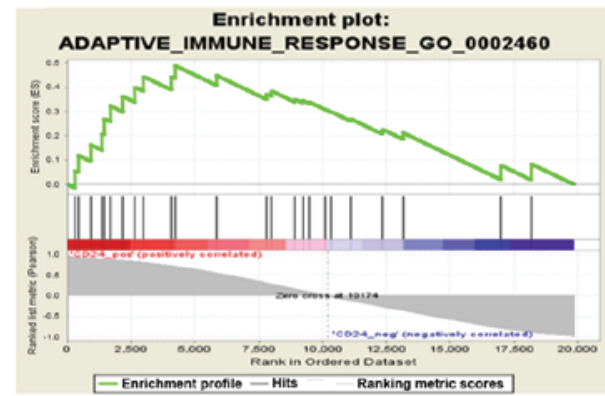

Table: GSEA Results Summary

\begin{tabular}{|l|l|}
\hline \hline Dataset & E-GEOD-14668.CD24 \\
\hline \hline Phenotype & CD24 \\
\hline \hline Upregulated in class & CD24_pos \\
\hline \hline GeneSet & KEGG_CALCIUM_SIGNALING_PATHWAY \\
\hline \hline Enrichment Score (ES) & 0.2939881 \\
\hline \hline Normalized Enrichment Score (NES) & 1.7905717 \\
\hline \hline Nominal p-value & 0.0 \\
\hline \hline FDR q-value & 0.009985557 \\
\hline \hline FWER p-Value & 0.258 \\
\hline
\end{tabular}

Table: GSEA Results Summary

\begin{tabular}{|l|l|}
\hline Dataset & E-GEOD-14668.CD24 \\
\hline \hline Phenotype & CO24 \\
\hline \hline Upregulated in class & CD24_Dos \\
\hline \hline GeneSet & ADAPTIVE_IMMUNE_RESPONSE_GO_0002460 \\
\hline \hline Enrichment Score (ES) & 0.48902 \\
\hline \hline Normalized Enrichment Score (NES) & 1.9120568 \\
\hline \hline Nominal p-value & 0.0037453184 \\
\hline \hline FDR q-value & 0.013970568 \\
\hline \hline FWER p-Value & 0.347 \\
\hline
\end{tabular}

Figure 5. Bioinformatic analysis of the role of CD24 in $\beta$-cell function. (A) The role of CD24 in the calcium signaling pathway. (B) The role of CD24 in the adaptive immune response. CD, cluster of differentiation; GSEA, Gene Set Enrichment Analysis.

$\zeta$-chain-associated protein kinase 70 (ZAP70), platelet-activating factor receptor (PTAFR), transmembrane protein 14
(TMEM14) and SPOCK2 mRNA as previous studies have shown these genes are associated with the proliferation and 

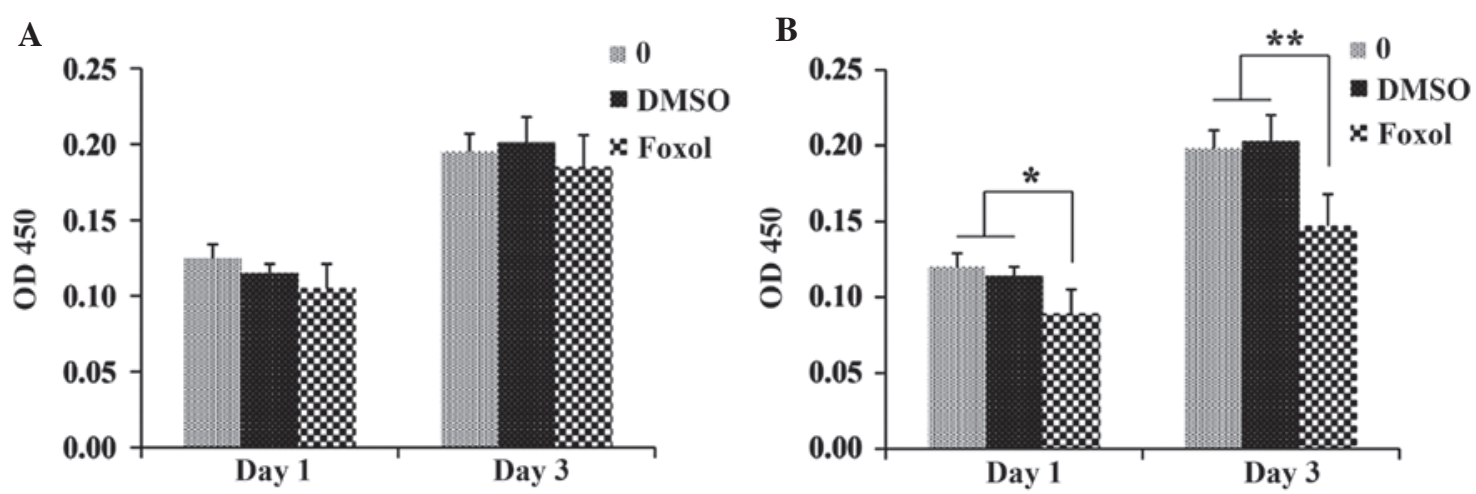

Figure 6. Overexpression of CD24 promotes INS-1 cell proliferation as assayed using a cell counting kit-8. (A) Proliferation tests of INS-1 cells treated with Foxo1 after the overexpression of CD24 on days 1 and 3. (B) The proliferation test of INS-1 cells treated with Foxo1 after the reverse transcription of control on days 1 and 3 . ${ }^{*} \mathrm{P}<0.05,{ }^{* *} \mathrm{P}<0.01$. CD, cluster of differentiation; fox, forkhead box; DMSO, dimethyl sulfoxide; OD, optical density.
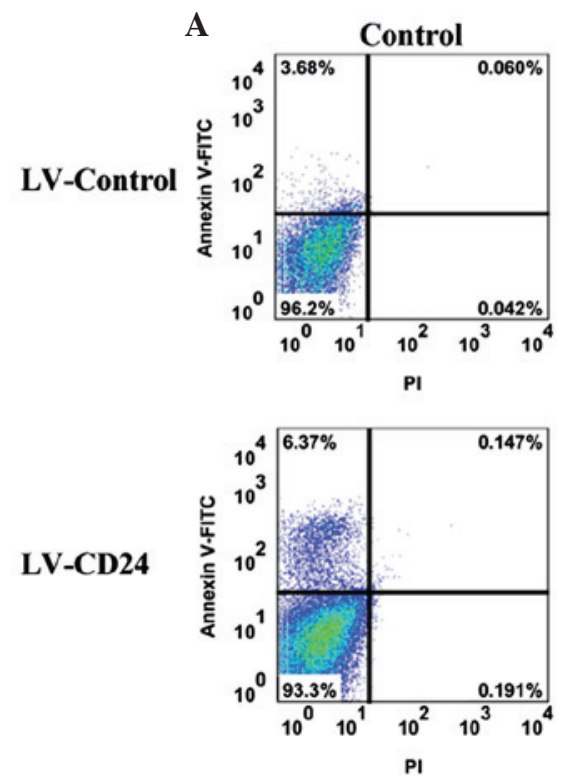

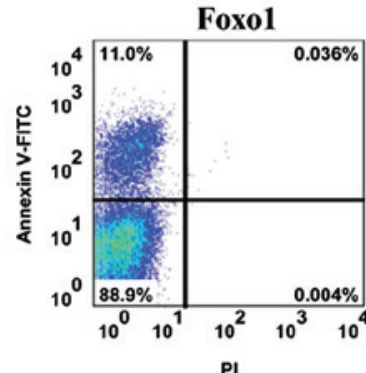

PI

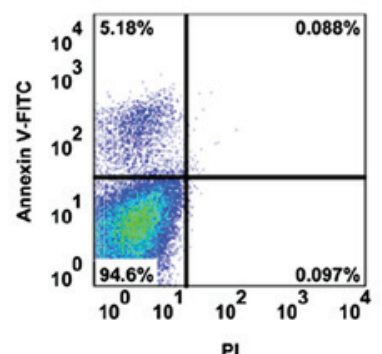

B

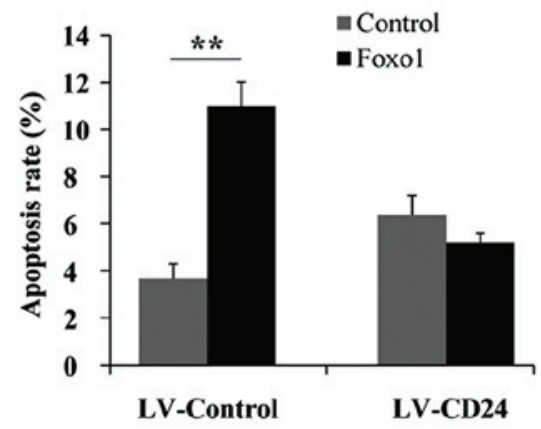

Figure 7. Overexpression of CD24 inhibits INS-1 cell apoptosis. (A) Flow cytometry showed the apoptosis rate of INS-1 cells treated with Foxo1 after the overexpression of either CD24 or control; DMSO treatment served as a control. (B) Quantitative analysis of apoptosis in INS-1 cells treated with Foxo1 after overexpression of CD24 or control. ${ }^{* *} \mathrm{P}<0.01$. CD, cluster of differentiation; fox, forkhead box; DMSO, dimethyl sulfoxide.

viability of tumor cells (19-23). Reactions were conducted on a DNA Engine Opticon 2 system (Bio-Rad Laboratories, Inc., Hercules, CA, USA). The thermocycling conditions were as follows: Initiation, $95^{\circ} \mathrm{C}$ for $2 \mathrm{~min} ; 40$ cycles at $95^{\circ} \mathrm{C}$ for $15 \mathrm{sec}$ and $60^{\circ} \mathrm{C}$ for $30 \mathrm{sec}$; and a melting curve stage of $60^{\circ} \mathrm{C}$ for $20 \mathrm{sec}$ and $95^{\circ} \mathrm{C}$ for $10 \mathrm{sec} . \beta$-actin served as a control to normalize relative expression of the target genes which was calculated using the $2^{-\Delta \Delta \mathrm{Cq}}$ method (24).

The primers used were as follows: 5'-TGCTCCTACCCA CGCAGATT-3' (sense) and 5'-GGCCAACCCAGAGTT GGAA-3' (antisense) for CD24; 5'-GTTGACTCATCCTCA GAGACGAATC-3' (sense) and 5'-AGGTTATCGCGCTTC AGGAA-3' (antisense) for ZAP70; 5'-GCTGCTCATTGG AGGGTAGA-3' (sense) and 5'-TGTGTCTCTGTCTGGGTC CT-3' (antisense) for PTAFR; 5'-GATAGTCAGCCCGTACG-3' (sense) and 5'-CGCATCGCCTTATGCGAT-3' (antisense) for TMEM14; 5'-GAGACGAAGTGGAGGATGACTA-3' (sense) and 5'-CTTGCAGATGGAGTCTTTGTTT-3' (antisense) for SPOCK2; 5'-GACTCATCGTCGTACTCCTGCTTGCTG-3' (sense) and 5'-GGAGATTACTGCCCTGGCTCCTA-3' (antisense) for $\beta$-actin.

Western blot analysis. Proteins were extracted from the pancreatic islets as previously described (11), concentration was determined using the Bradford assay and equal quantities of protein $(20 \mu \mathrm{g})$ were resolved by $10 \%$ sodium dodecyl sulfate-polyacrylamide gel electrophoresis. The proteins were transferred to nitrocellulose membranes and blocked in PBS with Tween 20 (Invitrogen; Thermo Fisher Scientific, Inc.; PBST) containing 5\% non-fat milk. The membranes were then incubated with CD24 primary antibodies for $12 \mathrm{~h}$ at $4^{\circ} \mathrm{C}$. The membranes were washed three times with PBST and incubated with HRP-conjugated secondary antibodies and washed a further three times with PBST. The protein bands were visualized using SuperSignal Pico ECL reagent (Pierce Biotechnology, Inc., Rockford, IL, USA). The membranes were reprobed with anti- $\beta$-actin antibody as loading controls and immunocomplexes were detected with Amersham ${ }^{\mathrm{TM}}$ ECL 
Prime Western Blotting Detection reagent (GE Healthcare Life Sciences, Chalfont, UK). The immunoblots were scanned and quantified using ImageTool 3.0 software (compdent.uthscsa. edu/dig/itdesc.html), the relative expression level of CD24 was normalized to $\beta$-actin expression.

Lentiviral vector carrying CD24 gene and infection. The lentiviral vector carrying the CD24 gene was purchased from Fujian Funeng Co., Ltd. (cat no. 20120810). The lentiviral system was used to produce INS-1 cells that stably overexpressed CD24. INS-1 cells were cultured in 24-well plates. When the cell confluence reached $90 \%$, the lentiviral vector (20 MOI) carrying the CD24 gene was added, and the plates were incubated for the indicated time at $37^{\circ} \mathrm{C}$ in a $5 \% \mathrm{CO}_{2}$ incubator.

Role of CD24 in $\beta$-cells on Gene Set Enrichment Analysis (GSEA). The dataset (E-GEOD-14668.CD24) used in this study was downloaded from the Broad Institute website (http://www.broadinstitute.org/gsea/index.jsp), and the entire data set with expression values was uploaded to the GSEA software (25) to explore the role of CD24 in $\beta$-cells and interpret the enrichment results.

Statistical analysis. Data processing and statistical analysis were performed using SPSS 19 (IBM SPSS, Armonk, NY, USA). Data are presented as the mean \pm standard error of the mean. Data from two groups were compared using Student's t-test and continuous variables between several groups were compared with one-way analysis of variance. $\mathrm{P}<0.05$ was considered to indicate a statistically significant difference.

\section{Results}

Foxol inhibits INS-1 proliferation. INS-1 cells were transfected with Foxo1, foxm1, foxp, foxa1, foxc or foxb1 to explore which of these factors effectively inhibited proliferation; pcDNA3 treatment served as the control. In all of the six tested FOX family genes, only Foxol significantly downregulated the expression of CD24 and inhibited INS-1 cell proliferation $(\mathrm{P}<0.01)$. As shown in Fig. 1, it was demonstrated that Foxo1 could effectively suppress the proliferation of INS-1 cells after 3 days of incubation, whereas the foxm1-, foxp-, foxa1-, foxc-, and foxb1-transfected cells did not show similar results. Moreover, the correlation between the concentration of Foxo1 and the proliferation rate of INS-1 cells was investigated as shown in Fig. 1B. The proliferation rate of INS-1 cells decreased with increases in the concentration of Foxol on day 1 and day 3 , and the proliferation rate of INS-1 cells in the $10 \mathrm{mM}$ Foxo1-treated group was significantly lower than those of the control and DMSO-treated groups on day $1(\mathrm{P}<0.05)$ and day $3(\mathrm{P}<0.01)$. A significant difference was also observed between the groups treated with 20 and $40 \mathrm{mM}$ Foxol and the control and DMSO groups on day $1(\mathrm{P}<0.01)$, and similar results were observed on day 3 . These results suggested that Foxol was able to inhibit INS-1 cell proliferation.

Foxol promotes INS-1 cell apoptosis. It was demonstrated that Foxo1 was able to inhibit INS-1 cell proliferation, and whether Foxol can promote INS-1 cell apoptosis. As shown in Fig. 2, the apoptosis rate of INS-1 cells increased with increasing concentrations of Foxo1. The apoptosis rate of INS-1 cells treated with $10 \mathrm{mM}$ Foxol was lower than that of the DMSO-treated group; however, this difference was not statistically significant. The apoptosis rate of INS-1 cells treated with 20 and $40 \mathrm{mM}$ Foxol was significantly higher than that of the DMSO-treated group $(\mathrm{P}<0.01)$. These results revealed that Foxol could promote INS-1 cell apoptosis.

Foxol suppresses CD24 expression in INS-1 cells. PCR arrays were used to screen the key signaling molecules that participate in this process. Five genes (CD24, ZAP70, PTAFR, TMEM14 and SPOCK2) were selected for analysis, and it was demonstrated that CD24 expression significantly decreased in the Foxo1-treated group compared with that of the DMSO-treated group (Fig. 3A). However, there was no significant decrease in the relative expression of ZAP70, PTAFR, TMEM14 or SPOCK2 $(\mathrm{P}=0.88, \mathrm{P}=0.92, \mathrm{P}=0.77$ and $\mathrm{P}=0.73$, respectively) CD24 expression was also measured in INS-1 cells after treatment with different concentrations of Foxo1, as shown in Fig. 3B. A negative correlation was identified between the expression of CD24 and the concentration of Foxo1. CD24 expression in the 10, 20 and $40 \mathrm{mM}$ Foxol-treated groups was significantly lower than that of the control and DMSO-treated groups $(\mathrm{P}<0.01)$. These results indicated that Foxo1 could inhibit CD24 expression.

CD24 is highly expressed in a diabetes model. Then, the expression level of CD24 was measured in the pancreatic islets of normal rats and of diabetic GK rats. As shown in Fig. 4, the expression levels of CD24 mRNA and protein were markedly higher in the diabetes model than in normal animals. This finding suggested that CD24 is highly expressed in the diabetic pancreas islet.

Bioinformatic analysis. Bioinformatic analysis indicated that CD24 participates in the calcium signaling pathway (Fig. 5A and $\mathrm{B}$ ) and is involved in the adaptive immune response of $\beta$-cells (Fig. 5C and D).

Overexpression of CD24 promotes INS-1 cell proliferation. Having demonstrated that Foxo1 inhibits INS-1 cell proliferation by suppressing CD24 expression, further studies were performed to evaluate the role of CD24 in INS-1 cell proliferation by reverse-transcribing CD24. Following overexpression of CD24, no significant difference in cell proliferation was observed in the Foxo1-treated group compared with the control and DMSO-treated groups on days 1 and 3. Whereas the proliferation rate was lower in the LV-Control-treated group than in the control and DMSO-treated groups on day 1 $(\mathrm{P}<0.05)$, a significant difference in cell proliferation was also observed in the LV-Control-treated group and in the control and DMSO-treated groups on day 3 ( $\mathrm{P}<0.01$; Fig. 6). These results revealed that CD24 is important in INS-1 cell proliferation.

Overexpression of CD24 inhibits INS-1 cell apoptosis. The apoptosis rate of INS-1 cells overexpressing CD24 following treatment with Foxol was also determined. As shown in Fig. 7, the apoptosis rate in the Foxol-treated group was significantly 
higher than that of the control reverse-transcribed group on day $3(\mathrm{P}<0.01)$. However, no obvious difference in the apoptosis rate was observed between the Foxol-treated group and the control group over-expressing CD24. These results indicated that CD24 is important in INS-1 cell apoptosis.

\section{Discussion}

The prevalence of diabetes mellitus is rapidly increasing worldwide. The global number of patients with diabetes mellitus is projected to rise to 439 million by 2030 , and $90 \%$ of these patients will have type 2 diabetes mellitus (26). Excessive apoptosis of $\beta$-cells is the primary cause of type 2 diabetes; however, the mechanism underlying this apoptosis remains unclear. Foxo1 is a transcription factor that is a member of the FOX family. It is important in multiple biological processes including oxidative stress, apoptosis and cell cycle arrest. Furthermore, Foxo1 is a tumor suppressor, which is downregulated in multiple types of tumor (27). Recent studies showed that the expression of the other five genes (CD24, ZAP70, PTAFR, TMEM14 and SPOCK2) are correlated with the proliferation and viability of tumor cells (19-23). A widely used cell line for islet $\beta$-cell function studies is the INS-1 cell line derived from the original radiation-induced tumor described by Chick et al (28) In the present study, a possible apoptotic mechanism in $\beta$-cells was identified, where Foxo1 overexpression promotes apoptosis by reducing CD24 expression. Therefore, this study demonstrated the important roles of Foxol and CD24 in $\beta$-cell apoptosis.

In the adult pancreas, Foxo1 is exclusively expressed in the islet $\beta$-cells (29). Foxo1 is a negative regulator of the transcription factor $\operatorname{Pdx} 1$, which is crucial in $\beta$-cell growth and function $(30,31)$. Foxol inactivation leads to increased Pdx1 expression and $\beta$-cell proliferation (10). By contrast, Foxo1 activation promotes apoptosis in $\beta$-cells. Roy et al (32). reported that the suppression of the PI3K/AKT and $\mathrm{MEK} / \mathrm{ERK}$ pathways activated foxo transcription factors, leading to cell cycle arrest and apoptosis in pancreatic cancer (32). Moreover, McLoughlin et al (33) found that Foxo1 enhances skeletal muscle atrophy by promoting skeletal muscle cell apoptosis via DNA binding-dependent and DNA binding-independent mechanisms. These results indicated that Foxol is key in the apoptosis of $\beta$-cells and of other cells. The results of the present study are consistent with this conclusion; Foxol overexpression promoted apoptosis in $\beta$-cells, and the inhibitory effects were enhanced with increasing Foxol concentrations.

CD24 is a glycoprotein that is expressed at the surface of the majority of $\beta$ lymphocytes and is essential in the immune system (34). In INS-1 cells treated with Foxo1 following overexpression of the control, proliferation was significantly reduced on day $1(\mathrm{P}<0.05)$ and day $3(\mathrm{P}<0.01)$, and the apoptosis rate was significantly increased $(\mathrm{P}<0.01$. However, no significant differences were observed following Foxo1 treatment of cells overexpressing CD24. This suggests overexpression of CD24 may block the effects of Foxo1 to promote INS-1 cell proliferation and inhibit apoptosis. The present results also confirmed this model and it was demonstrated that CD24 was associated with the adaptive immune response of $\beta$-cells. Furthermore, a previous study demonstrated that the expression of genes involved in the final steps of insulin secretion is reduced in patients with type 2 diabetes (35). One of the final steps in insulin secretion is the influx of $\mathrm{Ca}^{2+}$ through voltage-dependent $\mathrm{Ca}^{2+}$ channels, which triggers the exocytosis of insulin (36), and this calcium-triggered exocytosis results in the release of insulin from the secretory granules, which follows the $\mathrm{Ca}^{2+}$ influx through voltage-gated channels (37). Notably, it was demonstrated that CD24 was involved in the calcium signaling pathway, where this protein may regulate $\beta$-cell function.

In conclusion, in the present study, it was demonstrated that Foxol overexpression was able to promote $\beta$-cell apoptosis by decreasing CD24 expression, and the role of CD24 in $\beta$-cell function was preliminarily discussed. CD24 is involved in the calcium signaling pathway and in the adaptive immune response of $\beta$-cells. However, additional studies are required to clarify the role of CD24 in $\beta$-cell function.

\section{Acknowledgements}

The study was supported by the National Natural Science Foundation of China (nos. 81370904 and 81400785), Key Projects of Shanghai Municipal Health Bureau Research Fund (no. 2014Y015), Shanghai Jiao Tong University Research Funding on Medical and Engineering Interdisciplinary Projects (YG2015ZD08 and YG2015MS30), Wang Kuancheng Prize Fund for Medicine, Excellent Physician Fund Project of Shanghai General Hospital and Songjiang District Health Bureau of Climbing Medical Program (2014).

\section{References}

1. Chen L, Magliano DJ and Zimmet PZ: The worldwide epidemiology of type 2 diabetes mellitus-present and future perspectives. Nat Rev Endocrinol 8: 228-236, 2011.

2. Poitout DV and Robertson RP: An integrated view of beta-cell dysfunction in type-II diabetes. Annu Rev Med 47: 69-83, 1996.

3. Ahrén B: Type 2 diabetes, insulin secretion and beta-cell mass. Curr Mol Med 5: 275-286, 2005.

4. Karaskov E, Scott C, Zhang L, Teodoro T, Ravazzola M and Volchuk A: Chronic palmitate but not oleate exposure induces endoplasmic reticulum stress, which may contribute to INS-1 pancreatic beta-cell apoptosis. Endocrinology 147: 3398-3407, 2006.

5. Butler AE, Janson J, Bonner-Weir S, Ritzel R, Rizza RA and Butler PC: Beta-cell deficit and increased beta-cell apoptosis in humans with type 2 diabetes. Diabetes 52: 102-110, 2003.

6. Donath MY and Halban PA: Decreased beta-cell mass in diabetes: Significance, mechanisms and therapeutic implications. Diabetologia 47: 581-589, 2004.

7. Rhodes CJ: Type 2 diabetes-a matter of beta-cell life and death? Science 307: 380-384, 2005.

8. Kobayashi M,Kikuchi O, Sasaki T, Kim HJ, Yokota-Hashimoto H, Lee YS, Amano K, Kitazumi T, Susanti VY, Kitamura YI and Kitamura T: FoxO1 as a double-edged sword in the pancreas: Analysis of pancreas- and $\beta$-cell-specific FoxO1 knockout mice. Am J Physiol Endocrinol Metab 302: E603-E613, 2012.

9. Kitamura YI, Kitamura T, Kruse JP, Raum JC, Stein R, Gu W and Accili D: FoxO1 protects against pancreatic beta cell failure through NeuroD and MafA induction. Cell Metab 2: 153-163, 2005.

10. Kitamura T, Nakae J, Kitamura Y, Kido Y, Biggs WH III, Wright CV, White MF, Arden KC and Accili D: The forkhead transcription factor Foxol links insulin signaling to Pdx1 regulation of pancreatic beta cell growth. J Clin Invest 110: 1839-1847, 2002.

11. Buteau J, Spatz ML and Accili D: Transcription factor FoxO1 mediates glucagon-like peptide-1 effects on pancreatic beta-cell mass. Diabetes 55: 1190-1196, 2006 
12. Martinez SC, Tanabe K, Cras-Méneur C, Abumrad NA, Bernal-Mizrachi E and Permutt MA: Inhibition of Foxol protects pancreatic islet beta-cells against fatty acid and endoplasmic reticulum stress-induced apoptosis. Diabetes 57: 846-859, 2008.

13. Kristiansen G, Pilarsky C, Pervan J, Stürzebecher B, Stephan C, Jung K, Loening S, Rosenthal A and Dietel M: CD24 expression is a significant predictor of PSA relapse and poor prognosis in low grade or organ confined prostate cancer. Prostate 58: 183-192, 2004

14. Kristiansen G, Schlüns K, Yongwei Y, Denkert C, Dietel M and Petersen I: CD24 is an independent prognostic marker of survival in nonsmall cell lung cancer patients. Br J Cancer 88 : 231-236, 2003.

15. Liu W and Vadgama JV: Identification and characterization of amino acid starvation-induced CD24 gene in MCF-7 human breast cancer cells. Int J Oncol 16: 1049-1103, 2000.

16. Welsh JB, Zarrinkar PP, Sapinoso LM, Kern SG, Behling CA, Monk BJ, Lockhart DJ, Burger RA and Hampton GM: Analysis of gene expression profiles in normal and neoplastic ovarian tissue samples identifies candidate molecular markers of epithelial ovarian cancer. Proc Natl Acad Sci USA 98: 1176-1181, 2001.

17. Clark JD, Gebhart GF, Gonder JC, Keeling ME and Kohn DF: The 1996 guide for the care and use of laboratory animals. ILAR J 38: 41-48, 1997

18. Dong W, Ding X, Cai J, Peng Y, Wang Y and Tan J: Study on the standardization of islet isolation method in rats. Chin J Cell Stem Cell (Electronic Edition) 2: 237-240, 2012 (In Chinese).

19. Pei Z, Zhu G, Huo X, Gao L, Liao S, He J, Long Y, Yi H, Xiao S, Yi W, et al: $\mathrm{CD} 24$ promotes the proliferation and inhibits the apoptosis of cervical cancer cells in vitro. Oncol Rep: Dec 24, 2015 (Epub ahead of print).

20. Krenn PW,Hofbauer SW,Pucher S, HuttererE,Hinterseer E,Denk U, Asslaber D, Ganghammer S, Sternberg C, Neureiter D, et al: ILK induction in lymphoid organs by a TNF $\alpha-N F-\kappa B-r e g u l a t e d$ pathway promotes the development of chronic lymphocytic leukemia. Cancer Res: Feb 2, 2015 (Epub ahead of print).

21. Sahu RP: Expression of the platelet-activating factor receptor enhances benzyl isothiocyanate-induced apoptosis in murine and human melanoma cells. Mol Med Rep 12: 394-400, 2015.

22. Woo IS, Jin H, Kang ES, Kim HJ, Lee JH, Chang KC, Park JY, Choi WS and Seo HG: TMEM14A inhibits N-(4-hydroxyphenyl) retinamide-induced apoptosis through the stabilization of mitochondrial membrane potential. Cancer Lett 309: 190-198, 2011.

23. Ren F, Wang DB, Li T, Chen YH and Li Y: Identification of differentially methylated genes in the malignant transformation of ovarian endometriosis. J Ovarian Res: Jul 10, 2014 (Epub ahead of print).

24. Livak KJ and Schmittgen TD: Analysis of relative gene expression data using real-time quantitative PCR and the 2(-Delta Delta C(T)) method. Methods 25: 402-408, 2001
25. Subramanian A, Tamayo P, Mootha VK, Mukherjee S, Ebert BL, Gillette MA, Paulovich A, Pomeroy SL, Golub TR, Lander ES and Mesirov JP: Gene set enrichment analysis: A knowledge-based approach for interpreting genome-wide expression profiles. Proc Natl Acac Sci USA 102: 15545-15550, 2005.

26. Guariguata L, Whiting DR, Hambleton I, Beagley J, Linnenkamp U and Shaw JE: Global estimates of diabetes prevalence for 2013 and projections for 2035. Diabetes Res Clin Pract 103: 137-149, 2014.

27. Yu DA, Yoon J, Ko YS, Park J, Kim SY, Kim MA, Kim JH, Jung J, Cheon Y, Lee HS, et al: Forkhead transcription factor FOXO1 inhibits nuclear factor- $\mathrm{\kappa B}$ in gastric cancer. APMIS 122: 848-855, 2014.

28. Chick WL, Warren S, Chute RN, Like AA, Lauris V and Kitchen KC: A transplantable insulinoma in the rat. Proc Natl Acad Sci 74: 628-632, 1977.

29. Buteau J and Accili D: Regulation of pancreatic Beta-cell function by the forkhead protein FoxO1. Diabetes Obes Metab 9 (Suppl 2): S140-S146, 2007

30. Ahlgren U, Jonsson J, Jonsson L, Simu K and Edlund H: Beta-cell-specific inactivation of the mouseIpf $1 / \mathrm{Pdx} 1$ gene results in loss of the beta-cell phenotype and maturity onset diabetes. Genes Dev 12: 1763-1768, 1998.

31. Jonsson J, Carlsson L, Edlund $\mathrm{T}$ and Edlund $\mathrm{H}$ Insulin-promoter-factor 1 is required for pancreas development in mice. Nature 371: 606-609, 1994.

32. Roy SK, Srivastava RK and Shankar S: Inhibition of PI3K/AKT and MAPK/ERK pathways causes activation of FOXO transcription factor, leading to cell cycle arrest and apoptosis in pancreatic cancer. J Mol Signal 5: 10, 2010.

33. McLoughlin TJ, Smith SM, DeLong AD, Wang H, Unterman TG and Esser KA: FoxO1 induces apoptosis in skeletal myotubes in a DNA-binding-dependent manner. Am J Physiol Cell Physiol 297: C548-555, 2009.

34. Choi D, Lee HW, Hur KY, Kim JJ, Park GS, Jang SH, Song YS, Jang KS and Paik SS: Cancer stem cell markers CD133 and CD24 correlate with invasiveness and differentiation in colorectal adenocarcinoma. World J Gastroenterol 15: 2258-2264, 2009.

35. Andersson SA, Olsson AH, Esguerra JL, Heimann E, Ladenvall C, Edlund A, Salehi A, Taneera J, Degerman E, Groop L, et al: Reduced insulin secretion correlates with decreased expression of exocytotic genes in pancreatic islets from patients with type 2 diabetes. Mol Cell Endocrinol 364: 36-45, 2012.

36. Eliasson L, Abdulkader F, Braun M, Galvanovskis J, Hoppa MB and Rorsman P: Novel aspects of the molecular mechanisms controlling insulin secretion. J Physiol 586: 3313-3324, 2008.

37. Ammälä C, Eliasson L, Bokvist K, Larsson O, Ashcroft FM and Rorsman P: Exocytosis elicited by action potentials and voltage-clamp calcium currents in individual mouse pancreatic B-cells. J Physiol 472: 665-688, 1993. 